Licença CC BY: Artigo distribuído

sob os termos Creative Commons, permite uso e distribuição irrestrita em qualquer meio desde que o autor credite a fonte original.

\section{APLICAÇÃO DO PROGRAMA DE REGIONALIZAÇÃO DO TURISMO EM UMA INSTÂNCIA DE GOVERNANÇA REGIONAL NO ESTADO DO RIO GRANDE DO SUL, BRASIL}

\section{APLICACIÓN DEL PROGRAMA DE REGIONALIZACIÓN DEL TURISMO EN UNA INSTANCIA DE GOBERNANZA REGIONAL EN EL ESTADO DE RIO GRANDE DO SUL, BRASIL}

\author{
THIAGO REIS XAVIER' \\ KÉZIA ÁVILA SOARES TOTTI' \\ SANDRA MARI FLORES RADDATZ'
}
' UNIVERSIDADE FEDERAL DE SANTA MARIA, SANTA MARIA, RIO GRANDE DO SUL, BRASIL.

RESUMO: O presente estudo tem como objetivo analisar os mecanismos de governança turística do Fórum Regional de Turismo - Região Central, Rio Grande do Sul, Brasil. Trata-se de uma Instância de Governança Regional instituída para atender aos objetivos do Plano Nacional de Turismo (PNT) e do Programa de Regionalização do Turismo (PRT), e inserir a Região Central do Rio Grande do Sul no mapa do turismo brasileiro elaborado pelo Ministério do Turismo. Para tal, foi realizado um estudo de caso, qualitativo e descritivo, conduzido por meio de um roteiro de entrevistas semiestruturado elaborado a partir do modelo teórico proposto por Xavier (2016). Ele é organizado em seis categorias que abordam variáveis como: contexto histórico e cultural (1); formalização e estrutura, normas e regras (2); interação entre os atores e uso dos recursos locais (3); poder, confiança, conflito e interesses (4); transparência e prestação de contas (5); e Padrão de Arranjo Institucional (6). Como fontes foram selecionados três atores que atuaram como coordenadores do Fórum Regional de Turismo entre 2011 e 2018. A interpretação e a análise dos dados seguiram a metodologia de análise de conteúdo. Como resultados, observou-se que a falta de um Estatuto e de Plano Regional de Turismo prejudica as ações do Fórum, especialmente no que diz respeito à obtenção de recursos financeiros para desenvolvimentos de maiores práticas na região e elaboração de práticas conjuntas visando ao desenvolvimento do turismo regional. Sugerem-se a elaboração de um Plano Regional e a criação do estatuto interno, para que se possam viabilizar a formalização e as práticas de cooperação no âmbito do Fórum.

\footnotetext{
Thiago Professor Adjunto I do Curso de Gestão de Turismo da Universidade Federal de Santa Maria. Universidade Federal de Santa Maria, Santa Maria, RS, Brasil. E-mail: thiago.xavier@ufsm.br. Orcid: https:// orcid.org/0000-0003-0956-0605.

Kézia Tecnóloga em Gestão de Turismo pela Universidade Federal de Santa Maria (UFSM). Universidade Federal de Santa Maria, Santa Maria, RS, Brasil. E-mail: keziatotti@hotmail.com. ORCID: https://orcid. org/0000-0001-9014-0012:

Sandra Tecnóloga em Gestão de Turismo pela Universidade Federal de Santa Maria (UFSM). Universidade Federal de Santa Maria, Santa Maria, RS, Brasil. E-mail: sandramariraddatz@gmail.com. Orcid: https:// orcid.org/0000-0002-8193-7772.
} 
PALAVRAS-CHAVE: Governança. Governança turística. Regionalização. Instância de Governança. Fórum Regional de Turismo.

\begin{abstract}
This study aims to analyze the mechanisms tourist governance of the Regional Tourism Forum, located in the Rio Grande do Sul Central Region, Brazil. The study focuses on a Regional Governance entity created through the National Tourism Plan (PNT) and the Tourism Regionalization Program (PRT), and adds the Central Region of Rio Grande do Sul to the Brazilian Tourism Map proposed by the Ministry of Tourism. A qualitative and descriptive case study was conducted. A semi-structured interview script was used, based on the theoretical model proposed by Xavier (2016). This model is organized into six categories: historical and cultural context (1); formalization and structure, norms and rules (2); interaction between actors and use of local resources (3); power, trust, conflict and interests (4); transparency and accountability (5); and Forms of Network Governance (6). Three coordinators of the Regional Tourism Forum were interviewed between 2011 and 2018. The data were analyzed using the methodology of content analysis. The results showed the lack of internal bylaws and Regional Tourism Plan. This makes it difficult to obtain financial resources to develop efficient practices in the region, and to elaborate joint practices of tourism regional development. It is therefore suggested that a Regional Plan and internal bylaws be created, as this would enable formalization and cooperation in the Forum.
\end{abstract}

KEYWORDS: Governance. Destination governance. Regionalization. Regional Governance Instance. Regional Tourism Forum.

RESUMEN: Este estudio tiene como objetivo analizar los mecanismos de gobernanza turística del Foro Regional de Turismo - Región Central, Rio Grande do Sul, Brasil. Es una Instancia de Gobernanza Regional establecida para cumplir con los objetivos del Plan Nacional de Turismo (PNT) y el Programa de Regionalización Turística (PRT), e insertar la Región Central de Rio Grande do Sul en el mapa turístico brasileño elaborado por el Ministro de Turismo. Para ello, se realizó un estudio de caso cualitativo y descriptivo, realizado a través de un guión de entrevista semiestructurado elaborado a partir del modelo teórico propuesto por Xavier (2016). Este se organiza en seis categorías que abordan variables como: contexto histórico y cultural (1); formalización y estructura, normas y reglas (2); interacción entre actores y uso de recursos locales (3); poder, confianza, conflicto e intereses (4); transparencia y rendición de cuentas (5); y Norma de arreglo institucional (6). Como fuentes, se seleccionaron tres actores que actuaron como coordinadores del Foro Regional de Turismo, entre 2011 y 2018. La interpretación y los análisis de los datos siguió la metodología de análisis de contenido. Como resultado, se observó que la falta de un Estatuto y un Plan Regional de Turismo perjudica las acciones del Foro, especialmente en lo que respecta a la obtención de recursos financieros para el desarrollo de mayores prácticas en la región y el desarrollo de prácticas conjuntas orientadas a turismo regional. Se sugiere la elaboración de un Plan Regional y la creación del estatuto interno, de manera que se posibiliten las prácticas de formalización y cooperación dentro del Foro.

PALABRAS CLAVE: Gobernanza. Gobernanza turística. Regionalización. Instancia de gobierno. Foro Regional de Turismo.

\title{
INTRODUÇÃO
}

O setor de viagens e turismo cresceu, em 2018,3,9\%, contribuindo com uma receita global de US\$ 8,8 trilhões e gerando 319 milhões de postos de emprego em todo mundo em 2018. Já, em termos brasileiros, a mesma fonte aponta que em 2018 o turismo contribuiu para $8,1 \%$ do PIB nacional, gerando 6,9 milhões de empregos, 0 
que corresponde a 7,5\% do total de trabalhos gerados no Brasil (World Travel \& Tourism Council [WTTC], 2020).

Como forma de aproveitar a tendência de crescimento da atividade turística, - Governo Federal, por meio do Ministério do Turismo, vem demonstrando uma preocupação em estabelecer estruturas institucionais descentralizadas que possuam a capacidade de gerenciar políticas, planos e projetos voltados para o setor, dentre os quais se pode citar, como exemplo, o Plano Nacional de Turismo (PNT) (Ministério do Turismo [MTur], 2013) e o Programa de Regionalização do Turismo (PRT) (MTur, 2007).

De maneira geral, pode-se dizer que o Plano Nacional de Turismo (PNT) visa estabelecer mecanismos que garantam estabilidade e confiança para a obtenção de licenças, autorizações, concessões e demais exigências do Estado para a instalação e a operação de empreendimentos turísticos no país (Brasil, MTur, 2013). Além disso, esse, por meio do Programa de Regionalização do Turismo (PRT), incentiva a criação de Instâncias de Governança Regionais, como forma de promover a descentralização do poder com base na gestão democrática e na participação social (Mtur, 2007).

Mais especificamente em relação ao PRT, conforme dados do Ministério do Turismo (2020) - que destaca a mais recente atualização do Mapa do Turismo Brasileiro, realizada em 2019 -, existem, no Brasil, 333 regiões turísticas instituídas, o que abrange um total de 2694 municípios regionalizados. Em contrapartida, nota-se que apenas 104 das Instâncias de Governança são formalizadas com CNPJ (31,23\% do total), o que aponta para uma carência acerca do melhor entendimento dos atores envolvidos nesses espaços sobre os procedimentos e os mecanismos que devem ser adotados para uma gestão mais eficiente das mesmas.

Neste sentido, tendo na criação de Instâncias de Governança um dos principais pilares do PRT, nota-se a relevância pela realização de estudos que visam debater como são constituídos tais espaços, essencialmente por permitir compreender as relações e as interações inerentes ao setor atividade que possa se tornar insustentável a logo prazo, caso seja mal planejada e administrada por aqueles que a promovem.

Conforme Fernandes e Coriolano (2015), a participação nas Instâncias de Governança locais deve ocorrer por meio da participação dos indivíduos (atores), organizados em grupo, orientados a interferir e fazer com que o poder seja compartilhado. Neste sentido, aqui, entende-se como governança a forma pela qual um relacionamento de cooperação é organizado, tratando dos seus mecanismos regulatórios (Theurl, 2005) e de todo o sistema de funcionamento - processos decisórios, níveis de autonomia, formas de solução de conflitos e de controle (Wegner, 2012).

Isso posto, o presente estudo tem como objetivo analisar os mecanismos de governança do Fórum Regional de Turismo da Região Central, Rio Grande do Sul, Brasil. Para tal, pretende-se analisar categorias que abordam o tema em epígrafe, destacandose elementos como: contexto histórico e cultural; formalização e estrutura, normas e regras; interação entre os atores e uso dos recursos locais; poder, confiança, conflito e interesses; transparência e prestação de contas; e Padrão de Arranjo Institucional; tendo como base conceitual o modelo teórico proposto por Xavier (2016). 
O Fórum Regional de Turismo da Região Central constitui uma Instância de Governança Regional, formada por dezoito municípios gaúchos - Agudo, Cachoeira do Sul, Dona Francisca, Faxinal do Soturno, Itaara, Ivorá, Julio de Castilhos, Nova Palma, Novo Cabrais, Paraíso do Sul, Pinhal Grande, Restinga Seca, Santa Maria, São João do Polêsine, São Pedro do Sul, São Sepé, Silveira Martins e Toropi; os quais são representados pelos Secretários Municipais, Diretores ou outros agentes ligados ao Poder Público municipal voltados para o turismo.

Essa Instância de Governança Regional tem como finalidade articular as demandas relativas ao planejamento do turismo dos municípios que compõem esse agrupamento regional e levá-las para discussão no Conselho Estadual de Turismo do Rio Grande do SUl (CONETUR). A mesma foi instituída para atender aos objetivos do PRT e inserir a Região Central do Rio Grande do Sul no Mapa do Turismo Brasileiro, elaborado pelo Ministério do Turismo; visando articular os municípios integrantes na tentativa de estabelecer ações regionais coletivas voltadas para a elaboração de políticas públicas voltadas para o desenvolvimento da atividade turística.

Pretende-se, com esta pesquisa, fornecer subsídios para que atores localizados em destinos turísticos identifiquem a necessidade de se organizar de maneira colaborativa e cooperativa em forma de rede. Espera-se oferecer insumos para que gestores recorram às discussões aqui expostas para estruturar, regulamentar e gerenciar governanças (novas ou já existentes) em regiões nas quais predominam a atividade turística, tendo como foco, essencialmente, as Instâncias de Governança Regional instituídas pelo PRT.

Este estudo encontra-se estruturado em oito seções, dentre as quais se inclui a introdução. A segunda seção discorre acerca de conceitos centrais relacionados à governança, enquanto a terceira evidencia como essa temática encontra-se inserida no campo do turismo. A seção quatro introduz o modelo teórico, a partir do qual serão fundamentadas as análises da pesquisa. Adiante, a seção cinco descreve os procedimentos metodológicos, enquanto as seções seis e sete apresentam, respectivamente, os resultados da pesquisa e as considerações finais. Por fim, são elencadas as referências bibliográficas.

\section{GOVERNANÇA}

Governança corresponde a um "conceito plural, que compreende não apenas a substância da gestão, mas a relação entre os agentes envolvidos, a construção de espaços de negociação e os vários papéis desempenhados pelos agentes do processo" (Fischer, 1996, p.19), se referindo a acordos e contratos negociados junto a uma multiplicidade de atores (Bobbio, 2005).

Sob esse ponto de vista, Suzigan, Garcia e Furtado (2007) relacionam governança à capacidade de coordenação que agentes (empresas, organizações, instituições) exercem sobre as inter-relações produtivas, comerciais e tecnológicas, influenciando diretamente no desenvolvimento de um arranjo local ou uma rede. 
Igualmente, Cassiolato e Lastres (2001) ressaltam que governança se baseia em práticas democráticas de intervenção e participação de diferentes atores no processo decisório, o que inclui empresas públicas, privadas, cidadãos e trabalhadores, consultores, centros de desenvolvimento tecnológico e institutos de P\&D.

Ao destacar o ambiente das relações organizacionais, Rodrigues e Malo (2006, p.32) salientam que governança pode ser vista como "poder partilhado ou ação coletiva gerenciada, sendo particularmente pertinente para tratar organizações de natureza cooperativa, democrática e associativa". Ponto de vista a partir do qual Wegner (2012, p.214) a entende como "'as regras do jogo' da cooperação", por meio da qual se estruturam as formas de organização e funcionamento de redes.

Isso posto, pondera-se que a governança está relacionada à forma como as redes são estruturadas e organizadas, abordando mecanismos regulatórios e de tomada de decisão adotados para "garantir os interesses dos membros e assegurar que as normas estabelecidas sejam cumpridas tanto pelos gestores quanto pelos participantes", sendo a "responsável por manter os participantes unidos e habilitar ações conjuntas" (Wegner, 2012, p.217).

Sob a mesma ótica, tem-se Theurl (2005), que trata a governança como a sistemática de funcionamento do arranjo cooperativo, o que abrange processos decisórios, níveis de autonomia, formas de solucionar conflitos, mecanismos de controle e de participação nas decisões que regulem as atividades desenvolvidas.

Para Villela e Pinto (2009), a governança deve ocorrer de forma participativa e dialógica, diferentemente das formas de intervenção tecnoburocrática e hierarquizada do Estado no século passado. Nesses preceitos, os autores a identificam como:

(...) a prática de uma gestão compartilhada de processos decisórios que conduz, a partir do consenso, as deliberações de uma dada rede, objetivando articular e facilitar ações do projeto de desenvolvimento traçado pelos próprios participantes. Assim, as decisões devem ser tomadas em conjunto, devido ao engajamento participativo de todos os envolvidos, sejam eles representantes do Estado, da sociedade civil e/ou das empresas. (Villela \& Pinto, 2009, p.1075).

Conforme Zaccarelli et al. (2008), a atuação coordenadora da governança encontra-se atrelada ao desenvolvimento competitivo dos arranjos organizacionais; o que, segundo Roth et al. (2012), constitui elemento-chave para que as redes se desenvolvam e tenham seus objetivos alcançados. Nesse sentido, Theurl (2005) atenta para a responsabilidade da governança por manter o equilíbrio em situações nas quais há interesses conflitantes ou informações assimétricas entre os atores envolvidos.

Para evitar que ocorram conflitos de interesses e assimetrias de informações, Villela e Pinto (2009, p.1075) defendem que na governança as decisões devem ser tomadas em conjunto, devido ao engajamento participativo de todos os envolvidos, sejam eles representantes do Estado, da sociedade civil e/ou das empresas. Contexto esse que, conforme Theurl (2005), torna necessário estabelecer procedimentos para a gestão da cooperação, incluindo regras de entradas e saídas, além de estruturas de comunicação. 
Nesses preceitos, com base nos argumentos aqui expostos, neste estudo partese da premissa de que a governança é o instrumento facilitador da colaboração, por meio do qual são estabelecidos os princípios e as regras, a partir dos quais os atores econômicos, sociais e políticos irão interagir e cooperar entre si. Para tal, devem ser estabelecidos mecanismos para que os relacionamentos sejam coordenados de maneira a possibilitar que um destino ou uma região se torne competitiva.

\section{GOVERNANÇA E TURISMO}

Neste estudo, parte-se da premissa de que o turismo representa um setor altamente complexo e formado por organizações fragmentadas (Wang \& Krakover, 2009), o que torna a atividade dependente do desenvolvimento formal e informal de relações de colaboração, cooperação, parcerias e redes (Brunelli, Macedo-Soares \& Silva, 2012), o que se entende que deve ocorrer por meio de uma governança.

Quando aplicado ao turismo, o termo governança é empregado, tanto no setor público como no privado, "para denominar qualquer movimento de 'descentralização' do processo decisório, com a participação de atores envolvidos nessa decisão" (Tomio \& Schmidt, 2014, p.716). Neste sentido, salientando a importância do estudo da governança voltada para o turismo, na sequência será realizada uma revisão do estado da arte da temática em questão.

De forma inicial, remete-se ao estudo conduzido por Yüksel, Bramwell e Yüksel (2005), que propuseram um modelo para avaliar a governança do turismo na Estância Costeira de Belek, na Turquia, defendendo o predomínio da descentralização e enfatizando questões relacionadas a: (a) distribuição de autoridade; (b) controle e poder; e (c) legitimidade política. Paralelamente, Svensson, Nordin e Flagestad (2005) consideraram que a perspectiva da governança é adequada para compreender a dinâmica do turismo, argumentando que esse setor possui características de (a) complexidade multiator (vários atores), (b) dependência de recursos entre os envolvidos e (c) interação (parcerias) público-privada.

Ao analisarem a experiência da introdução do Sydney Harbour Manager, ocorrida em 1998 na Austrália, Dawkins e Colebatch (2006) apresentaram um exemplo sobre como governar o turismo por meio da criação e por meio da institucionalização de redes, identificando que temas relevantes na abordagem sobre essas, são importantes para a análise do uso da governança no solo urbano.

Dredge (2006) publicou um estudo de caso em Lake Macquarie, New South Wales, na Austrália, no qual investigou as relações existentes entre o governo local e a indústria para discutir criticamente o papel dessas conexões na promoção ou na inibição da formação de parcerias público-privadas. Enquanto Novelli, Schmitz e Spencer (2006) defenderam que as redes de negócios em aglomerados seriam capazes de proporcionar oportunidades às pequenas e médias empresas inovadoras que desejam operar em ambiente de turismo competitivo e em um ambiente de negócios globalizado, utilizando o UK Healthy Lifestyle Tourism Cluster (HLTC) como referência de discussão do processo governança. 
Pforr (2006) demonstrou a utilidade da governança para descrever, analisar e explicar como os atores públicos, privados e sem fins lucrativos modelaram os processos de formulação de políticas na formação geográfica e social do Território Norte de Desenvolvimento do Turismo Masterplan, da Austrália. Ao explorar e detalhar a estrutura relacional dos atores que moldam o Território Norte na formulação de políticas de turismo, o estudo focou na influência da reputação na cooperação e na comunicação (elementos que estão na base do processo de formulação de um plano diretor do turismo) para mapear a intensidade e a densidade das relações e avaliar se e como as partes interessadas tomam uns aos outros em consideração a suas ações.

Beritelli, Biegere Laesser (2007) analisaram e avaliaram doze localidades nos Alpes suíços, explicando por meio de um estudo qualitativo as estruturas de governança das destinações e sua evolução, embasando suas análises em seis dimensões, originalmente utilizadas em análises de modelos envolvendo relações corporativas, mas que poderiam ser operacionalizadas na análise de destinos turísticos: (a) custos de transação; (b) assimetria de poder; (c) interdependência; (d) confiança; (e) conhecimento; e (f) conexões pessoais e informais.

Nordin e Svensson (2007) realizaram um estudo de caso na Estância de Esqui sueca de Are, explorando o impacto exercido pela governança no desenvolvimento desse destino, tendo como foco: (a) as relações público-privadas, (b) as redes formais e informais e (c) as dependências de recursos. Para eles, as interações regulares entre os stakeholders locais são frequentemente causadas devido a sua necessidade de compartilhar e trocar recursos (informações, confiança, experiência); carência essa que evidencia a existência de dependências entre os atores do destino que constituem fatores importantes e que precisam ser compreendidos.

Conforme Nordin e Svensson (2007), as interações público-privadas, ou seja, as relações formais e informais entre governo e a indústria do turismo podem ser de importância crucial para o desenvolvimento local, sendo que a perspectiva de governança poderia dar a contribuição necessária para o desenvolvimento dessa dinâmica de relacionamento.

Posteriormente, Eagles (2009) estudou 8 casos de governança utilizados em parques e áreas protegidas, apontando três elementos comumente presentes na gestão de unidades de conservação: (1) a propriedade dos recursos; (2) as fontes de renda existentes para a gestão; e (3) o órgão de administração. Na pesquisa foram apontados 10 critérios para avaliar a governança nessas áreas, apontando que o contexto histórico e cultual desempenha um papel importante na escolha do modelo de governança.

No ano seguinte, Beaumont e Dredge (2010) focaram na eficácia de vários modos de governança de destino, identificando características vistas por eles como sendo de "boa governança", elencando os seguintes parâmetros: (a) culturas positivas, comunicação construtiva e comunidades envolvidas; (b) transparência e prestação de contas; (c) visão e liderança; (d) aceitação da diversidade e busca da equidade e inclusão; (e) desenvolvimento de conhecimento, aprendizagem e partilha de conhecimentos especializados; (f) papéis e responsabilidades dos participantes, estruturas operacionais e processos da rede claros. 
D'Angella, De Carlo e Sainaghi (2010) propuseram um modelo por meio do qual procuraram analisar a governança de destinos considerando mecanismos e estruturas úteis para o estabelecimento de um equilíbrio justo entre as contribuições fornecidas e recompensas obtidas por cada parte interessada.

Ruhanen (2010) analisou e sintetizou 53 estudos publicados sobre governança, identificando 40 dimensões separadas, das quais foram destacadas as seis mais frequentes e que poderiam ser adaptadas em estudos sobre destinos turísticos: (1) responsabilidade, (2) transparência, (3) participação, (4) estrutura, (5) eficácia e (6) poder.

Também sobre governança, Haugland et al. (2011) desenvolveram um quadro teórico destacando três áreas específicas, que interligadas poderiam afetar o desenvolvimento do destino: (1) as capacidades do destino; (2) a coordenação ao nível de destino; e (3) a ponte de laços entre destinos.

Com foco nas relações e nas interdependências entre os atores locais no turismo, Pan (2012) desenvolveu um estudo com o objetivo de compreender a governança em Marstrand, resort à beira-mar localizado no oeste da Suécia, e descobrir aqueles que exerciam influência no processo. No estudo, o autor teve como foco dimensões que se encontram ligadas e se sobrepõem umas às outras em alguns pontos: (a) poder, (b) confiança e (c) conflitos na formação da rede.

Dimensões por meio das quais Beritelli e Bieger (2014) elaboraram um construto de pesquisa abordando aspectos relacionados à liderança e à governança. Eles propuseram uma mudança da perspectiva individualista, mais intraorganizacional (única instituição/organização), para uma perspectiva sistêmica (interorganizacional), que considere as estruturas, as regras e as normas e permita a compreensão da liderança, ou seja, quem exerce influência e ação.

Com base na revisão bibliográfica aqui construída, compreende-se que a governança que envolve o turismo possui particularidades e interdisciplinaridades inerentes ao setor, afetando esferas da economia e da sociedade, podendo gerar impactos sociais negativos e tornar a atividade insustentável a longo prazo, caso seja mal planejada e administrada por aqueles que a promovem.

Isso posto, de maneira geral, a partir da literatura sobre o tema, observa-se que predominam temas relacionados a: (a) dimensões da governança, (b) formalização, (c) estrutura, normas e regras, (d) interações e parcerias, especialmente as público-privadas, (e) dependências de recursos, (f) relações de poder, conflito e confiança, (g) mecanismos de transparência e prestação de contas, (h) formas e estrutura da governança (padrão institucional) e (g) necessidade de uma agência de governança local.

\section{MODELO TEÓRICO DE ESTUDO}

Nesta seção, expõe-se o conjunto de dimensões e de variáveis de análise a partir das quais se sustenta o modelo teórico proposto por Xavier (2016) - o qual servirá de base para condução deste estudo. Esse foi construído a partir de uma sequência de etapas, que serão descritas na sequência: (a) contexto local para governança; (b) funcionamento da governança; (c) desenvolvimento da governança; (d) 
coordenação da cooperação na governança; (e) resultados da governança; e (f) Padrão de Arranjo Institucional.

\section{CONTEXTO local PARA A GOVERNANÇA}

Por meio de uma revisão teórica, Xavier (2016) identificou a necessidade por se observar aspectos que correspondem ao contexto local no qual se constituiu o processo de governança. Nesse construto, considera-se a relevância do (a) contexto histórico e cultural que deu origem ao cooperativo e da identificação dos (b) atores locais historicamente envolvidos no processo de colaboração.

Com relação ao contexto histórico e cultural, Beritelli, Bieger e Laesser (2007) e Eagles (2009) defendem que o histórico das relações entre indivíduos e instituições pode fornecer insumos importantes para que se possa compreender o modelo por meio do qual se estrutura a governança local.

Por outro lado, Svensson, Nordin e Flagestad (2005), Dredge (2006) e Beritelli, Bieger e Laesser (2007) ressaltam aspectos referentes à necessidade de se conhecer e analisar os atores envolvidos no processo de governança. Sobre esses, D'Angella, De Carlo e Sainaghi (2010) consideram relevante entender como os integrantes foram selecionados, o que pode vir a incluir entidades públicas e privadas que realizem pagamentos de taxas ou tenham seu envolvimento formalizado.

\section{FUnCIONAMENTO DA GOVERNANÇA}

Ao observar o processo de funcionamento da governança, ou seja, como essa é colocada em prática pelos seus atores, Xavier (2016) ressalta a necessidade de se discutir aspectos relacionados a (a) formalização e (b) estrutura, normas e regras.

Sobre a formalização da governança, há as contribuições de Dredge (2006), Nordin e Svensson (2007), D'Angella, De Carlo e Sainaghi (2010) e Haugland et al. (2011), segundo os quais há a necessidade de se atentar para a possibilidade de existência, tanto de relações formais quanto informais de coesão.

Já no que diz respeito à estrutura, às normas e às regras da governança, Dredge (2006) aponta que se deve compreender como são tratados os seguintes aspectos: a negociação e a acomodação de interesses conflitantes; a promoção de um sentimento comum de bem-estar e a compreensão mútua, evitando disputas ideológicas; o acesso ao processo de tomada de decisão, consulta e troca entre os participantes; e a cooperação na formulação de políticas.

Nesse sentido, Haugland et al. (2011) evidenciam a necessidade pela implementação de mecanismos de coordenação (contratos, estruturas de governança e regras formais) como forma de inibir a ocorrência de situações que possam vir dificultar a cooperação e, consequentemente, comprometer a governança.

Por fim, D'Angella, De Carlo e Sainaghi (2010) ressaltam ser importante analisar como são gerenciados os seguintes pontos: (a) o estimulo à participação das partes 
individuais interessadas em um projeto de desenvolvimento compartilhado; (b) a formalização dos mecanismos de coordenação entre a governança e as partes interessadas; (c) a seleção de novos membros e a saída de outros; (d) a identificação de mecanismos de acompanhamento e a determinação de possíveis sanções para o comportamento oportunista por parte dos membros; e (e) a definição de mecanismos de contribuição para a governança e a divisão de resultados.

\section{DESENVOLVIMENTO DA GOVERNANÇA}

A importância do construto desenvolvimento da governança foi observada a partir do estudo realizado por Haugland et al. (2011), que observaram três áreas específicas, que interligadas poderiam afetar o desenvolvimento do destino: (a) a coordenação em nível de destino; (b) as capacidades; e (c) as pontes de laços entre destinos.

No que diz respeito à coordenação em nível de destino, Haugland et al. (2011) relataram ser necessário compreender o grau de interações existentes entre os atores políticos, sociais e econômicos na estrutura da rede de turismo local.

Quando se referem à dimensão capacidades do destino, Haugland et al. (2011) apontam para a propriedade de o turismo estar diretamente relacionado ao uso dos recursos distribuídos no destino e das competências entre os atores.

Xavier (2016) agregou a essa dimensão as considerações de Svensson, Nordin e Flagestad (2005), Dredge (2006) e Nordin e Svensson (2007), que também abordaram o uso dos recursos do destino. Segundo esses autores, as interações entre os atores decorrem da sua necessidade de trocar/compartilhar recursos e competências, as quais se encontram relacionadas às capacidades turísticas locais, à imagem e à marca do destino.

Por fim, há as pontes de laços entre destinos, vistas por Haugland et al. (2011) como relações com outros destinos ou regiões turísticas visando à imiłação ou à difusão de práticas inovadoras e bem-sucedidas em outras localidades.

\section{COORDENAÇÃO DA COOPERAÇÃO NA GOVERNANÇA}

A dimensão coordenação da cooperação na governança foi notada nos estudos de Pan (2012), os quais tiveram como foco as seguintes dimensões: (a) relações de poder; (b) confiança/controle; (c) conflito; e (d) interesse.

As relações de poder também foram observadas por Dredge (2006), que ressaltou pontos tais como a existência de interesses comerciais divergentes e de autonomia por parte do Estado e privados. Conforme o autor, esses elementos - caso presentes - poderiam gerar desequilíbrios entre os grupos de interessados. Sobre este aspecto, Fernandes e Coriolano $(2015$, p.274) salientam que "fomentar a participação não é o mesmo que efetivar o compartilhamento do poder, ou seja, a governança".

Também sobre as relações de poder, Beritelli, Bieger e Laesser (2007) salientam que a composição diversa da rede no turismo pode vir a gerar a existência de fontes 
de domínio diversas, derivadas da sua capacidade de formar subgrupos de interesse e domínio sobre as propriedades.

Em terceiro lugar, no que diz respeito à confiança, dimensão observada por Beritelli, Bieger e Laesser (2007), pondera-se sobre a importância em garantir que exista no grupo um sentimento de segurança mútuo. Neste sentido, Pan (2012) ressalta que se deve compreender as relações e os interesses das partes envolvidas no processo de cooperação, como forma de evitar a existência de ações conflituosas entre os interessados.

\section{RESULTADOS DA GOVERNANÇA}

Construto resultados da governança foi divido em (a) transparência e prestação de contas e (b) compensações obtidas. A primeira dimensão em questão foi observada nos estudos da OMT (2010) e de Duran (2013), os quais atentaram para a importância de existência de ações, práticas ou procedimentos para a realização de metas coletivas, prestação de contas e avaliação de resultados.

Conforme Tomio e Schmidt (2014, p.734), "todo o processo de desenvolvimento envolve investimentos, por isso os custos de um processo que promove ações conjuntas devem ser transparentes". Nesses preceitos, os autores ressaltam a importância pelo reconhecimento do papel de cada autor envolvido e suas responsabilidades, além dos investimentos que serviram para efetivar as iniciativas, que também acompanharão esta cobrança.

Além desses, as compensações obtidas foram tratadas por D'Angella, De Carlo e Sainaghi (2010), que destacam ser necessário deixar claras as recompensas a serem obtidas pelos envolvidos, evidenciando que essas dependem do desempenho geral da governança, devendo-se observar o retorno obtido pela participação e a coerência desse benefício com as necessidades da organização e da governança.

\section{Padrão de Arranjo Institucional}

Conforme proposto por Xavier (2016), neste momento deve-se analisar o Padrão de Arranjo Institucional. Para tal, o autor se baseia nos estudos de D' Angella, De Carlo e Sainaghi (2010), que identificaram a existência de quatro padrões de arranjo institucional: (a) normativo; (b) empresarial; (c) empresa-líder; e (d) fragmentado.

Conforme descrevem D'Angella, De Carlo e Sainaghi (2010), o padrão normativo se baseia na centralidade de uma autoridade local (pública ou privada), que determina as normas que regulam as estruturas e os mecanismos de participação. O empresarial centra-se em uma adesão voluntária pelos diferentes parceiros envolvidos na oferta turística local, sejam eles empresas públicas ou instituições privadas. A empresalíder ressalta que a governança do destino é baseada em uma única entidade representada por uma empresa líder ou instituição local; enquanto o fragmentado resulta do desenvolvimento espontâneo do turismo, devido à presença de recursos locais privilegiados. 
Sob outra ótica, Wegner (2011) evidencia que a governança em redes interorganizacionais pode ser discutida sob duas visões: (1) descrevendo macroestruturas, tendo como foco analisar "quem" é autorizado pela rede a gerenciar as atividades centrais e as implicações dessas - visão discutida por Provan e Kenis (2008) - e (2) descrevendo microestruturas, concentrando-se em discutir "como" e "de que maneira" a governança é realizada internamente, além dos resultados para o grupo-abordagem proposta por Albers (2010) e Theurl (2005).

Com relação às macroestruturas, pode-se destacar Provan e Kenis (2008), que apontam para a possibilidade de um modelo mais simples, denominado Governança Compartilhada, no qual as organizações trabalham coletivamente sem a existência de uma instituição administrativa formalizada ou exclusiva. Nesse modelo, Wegner (2011, p.53) ressalta que "a governança ocorre através de reuniões dos representantes das empresas ou mesmo informalmente, através das ações daqueles que tem interesse no sucesso da rede".

Provan e Kenis (2008) evidenciam, também, a existência de um segundo modelo, formado por uma Organização Líder, que, maior e mais poderosa, estabelece relacionamentos verticais com um grupo composto por outras menores e mais fracas. Enquanto, como uma terceira opção, os mesmos destacam a possibilidade de se criar uma Organização Administrativa da Rede (OAR), que pode atuar como uma entidade separada responsável por coordenar as decisões-chave da rede e gerenciar o relacionamento entre os membros.

Para Wegner (2012, p.216), a OAR pode ser "modesta, consistindo somente em um indivíduo, ou pode ser uma forma organizacional mais complexa, com executivos e equipes de apoio operando em um escritório da rede" (Figura 1).

Figura 1: Modelos básicos de governança

Compartilhada

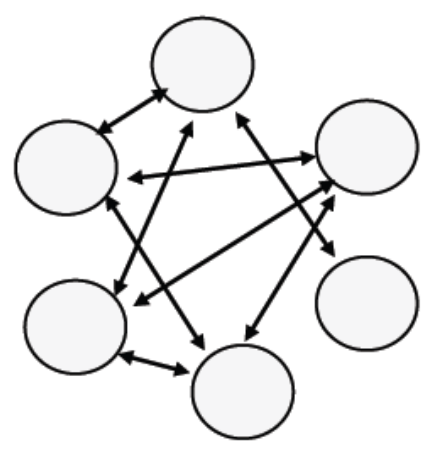

Organização Líder

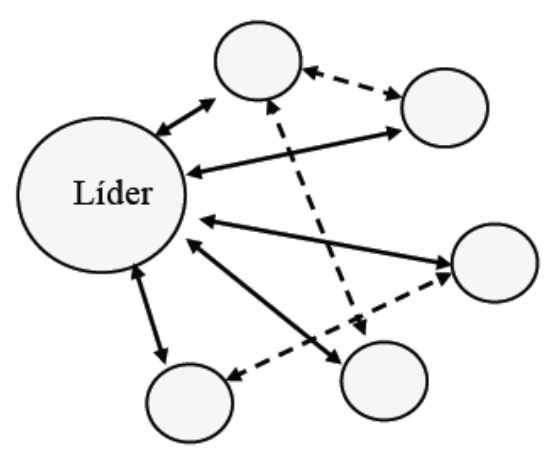

Organização

Administrativa da Rede

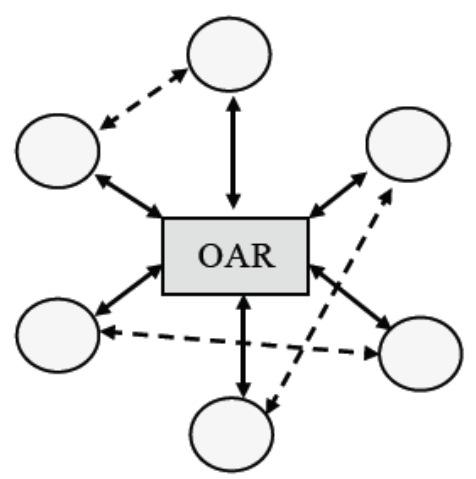

Fonte: Wegner (2011), formada a partir de Provan e Kenis (2008).

Considerados os modelos básicos apresentados pela Figura 1, Wegner (2012, p.217) ressalta que podem se desenvolver "formas híbridas ou estruturas transitórias, modificadas à medida que a rede se desenvolve". 
Isso posto, tendo como base as dimensões descritas ao longo desta seção, o Quadro 1 apresenta uma síntese dos principais pontos abordados no modelo teórico proposto por Xavier (2016).

Quadro 1: Quadro teórico proposto para o estudo.

\begin{tabular}{|c|c|c|c|}
\hline Construto & Dimensões & Propriedades e implicações & Autores pesquisados \\
\hline \multirow[b]{2}{*}{ 1) Contexto local } & $\begin{array}{l}\text { Contexto } \\
\text { histórico e } \\
\text { cultural }\end{array}$ & $\begin{array}{l}\text { Conhecer a história do } \\
\text { destino e das relações entre } \\
\text { os atores locais e instituições. } \\
\text { Compreender os motivos e } \\
\text { as situações que levaram } \\
\text { ao surgimento e à atual } \\
\text { configuração do processo de } \\
\text { governança. }\end{array}$ & $\begin{array}{l}\text { Beritelli, Bieger e Laesser (2007); } \\
\text { Eagles (2009) }\end{array}$ \\
\hline & Atores locais & $\begin{array}{l}\text { Identificar o número e o } \\
\text { tipo de atores envolvidos. } \\
\text { Assegurar a participação } \\
\text { da complexidade multiator } \\
\text { inerente ao turismo se faz } \\
\text { importante para garantir } \\
\text { que a diversidade de setores } \\
\text { que envolve o turismo seja } \\
\text { contemplada. }\end{array}$ & $\begin{array}{l}\text { Svensson, Nordin e Flagestad } \\
\text { (2005); Dredge (2006); Beritelli, } \\
\text { Bieger e Laesser (2007); } \\
\text { D'Angella, De Carlo e Sainaghi } \\
\text { (2010) }\end{array}$ \\
\hline \multirow[b]{2}{*}{$\begin{array}{l}\text { 2) Funcionamento } \\
\text { da governança }\end{array}$} & Formalização & $\begin{array}{l}\text { Possibilidade de existência de } \\
\text { relações formais e informais } \\
\text { de coesão. Acredita-se que } \\
\text { as relações formais e informais } \\
\text { possuem um papel relevante } \\
\text { para o desenvolvimento do } \\
\text { turismo, pois a formalização } \\
\text { poderia conferir estabilidade } \\
\text { à rede e trazer benefícios } \\
\text { para a mesma. }\end{array}$ & $\begin{array}{l}\text { Dredge (2006), Nordin e } \\
\text { Svensson (2007), D'Angella, } \\
\text { De Carlo e Sainaghi (2010) e } \\
\text { Haugland et al. (2011) }\end{array}$ \\
\hline & $\begin{array}{c}\text { Estrutura, normas } \\
\text { e regras }\end{array}$ & $\begin{array}{l}\text { Identificar integrantes, } \\
\text { requisitos de adesão, processo } \\
\text { de tomada de decisão, } \\
\text { mecanismos de negociação, } \\
\text { coordenação e troca entre } \\
\text { os participantes, além das } \\
\text { formas de cooperação na } \\
\text { formulação de políticas. } \\
\text { Observar os instrumentos } \\
\text { normativos existentes, visando } \\
\text { à negociação de interesses } \\
\text { conflitantes; o sentimento } \\
\text { comum de bem-estar público; } \\
\text { a compreensão mútua e as } \\
\text { disputas ideológicas. }\end{array}$ & $\begin{array}{l}\text { Dredge (2006); D' Angella, De } \\
\text { Carlo e Sainaghi (2010); OMT } \\
\text { (2010); Haugland et al. (2011) }\end{array}$ \\
\hline
\end{tabular}




\begin{tabular}{|c|c|c|c|}
\hline \multirow{3}{*}{$\begin{array}{l}\text { 3) Desenvolvimento } \\
\text { da governança } \\
\text { (Haugland et al., } \\
\text { 2011) }\end{array}$} & $\begin{array}{l}\text { Coordenação } \\
\text { (Interaçōes/ } \\
\text { Parcerias) }\end{array}$ & $\begin{array}{l}\text { Entender o grau de interação } \\
\text { na estrutura de rede local, } \\
\text { entre os atores políticos, } \\
\text { sociais e econômicos, e entre } \\
\text { o governo local e a indústria. } \\
\text { Pretende-se observar também } \\
\text { as formas de interações } \\
\text { existentes: (a) convencional } \\
\text { ou individualista, (b) } \\
\text { administrada, (c) contratual e } \\
\begin{array}{ll}\text { (d) corporativa. } & \end{array}\end{array}$ & $\begin{array}{l}\text { Svensson, Nordin e Flagestad } \\
\text { (2005), Nordin e Svensson } \\
\text { (2007), OMT (2010), Pan (2012); } \\
\text { Duran (2013) e Haugland et al. } \\
\text { (2011). }\end{array}$ \\
\hline & $\begin{array}{l}\text { Capacidades } \\
\text { do destino } \\
\text { (Dependência de } \\
\text { recursos) }\end{array}$ & $\begin{array}{l}\text { Observar como ocorre } \\
\text { a utilização dos recursos } \\
\text { distribuídos e competências. } \\
\text { Parte-se da premissa de que } \\
\text { as interações entre os atores } \\
\text { locais são frequentemente } \\
\text { causadas devido à existência } \\
\text { de dependência de recursos } \\
\text { e competências entre os } \\
\text { envolvidos. }\end{array}$ & $\begin{array}{l}\text { Svensson, Nordin e Flagestad } \\
\text { (2005), Dredge (2006); Nordin e } \\
\text { Svensson (2007) e Haugland et } \\
\text { al. (2011). }\end{array}$ \\
\hline & $\begin{array}{l}\text { Pontes de laços } \\
\text { entre destinos }\end{array}$ & $\begin{array}{l}\text { Identificar a possível existência } \\
\text { de relações com outros } \\
\text { destinos turísticos poderia } \\
\text { possibilitar a imitação ou a } \\
\text { difusão de práticas inovadoras } \\
\text { e bem-sucedidas. }\end{array}$ & Haugland et al. (2011) \\
\hline \multirow{4}{*}{$\begin{array}{l}\text { 4) Coordenação } \\
\text { da cooperação na } \\
\text { governança (PAN, } \\
\text { 2012) }\end{array}$} & $\begin{array}{l}\text { Relações de } \\
\text { poder }\end{array}$ & $\begin{array}{l}\text { Observar a possível existência } \\
\text { de assimetrias de poder } \\
\text { resultantes da divergência } \\
\text { de interesses comerciais e } \\
\text { privados entre os diferentes } \\
\text { grupos de atores envolvidos. }\end{array}$ & $\begin{array}{l}\text { Dredge (2006); Beritelli, Bieger } \\
\text { e Laesser (2007); Pan (2012); } \\
\text { Fernandes e Coriolano (2015) }\end{array}$ \\
\hline & $\begin{array}{l}\text { Confiança/ } \\
\text { controle }\end{array}$ & $\begin{array}{l}\text { A importância da existência } \\
\text { de confiança mútua decorre } \\
\text { da necessidade de possibilitar } \\
\text { que as decisões, as ações e } \\
\text { o controle social sejam, pelo } \\
\text { menos, tão fortes como o } \\
\text { controle institucional. }\end{array}$ & $\begin{array}{l}\text { Beritelli, Bieger e Laesser (2007); } \\
\text { Pan (2012) }\end{array}$ \\
\hline & Conflito & $\begin{array}{l}\text { Necessidade de compreender } \\
\text { as relações das partes } \\
\text { envolvidas no processo de } \\
\text { cooperação como forma de } \\
\text { evitar a existência de ações } \\
\text { conflituosas entre as partes } \\
\text { interessadas. }\end{array}$ & Pan (2012) \\
\hline & Interesse & $\begin{array}{l}\text { Importância de detectar } \\
\text { os interesses individuais que } \\
\text { motivaram a participação } \\
\text { dos atores no processo de } \\
\text { cooperação. A existência de } \\
\text { interesses divergentes poderá } \\
\text { causar ações conflituosas } \\
\text { dentro da governança. }\end{array}$ & Pan (2012) \\
\hline
\end{tabular}




\begin{tabular}{|c|c|c|c|}
\hline \multirow[b]{2}{*}{$\begin{array}{l}\text { 5) Resultados da } \\
\text { governança }\end{array}$} & $\begin{array}{c}\text { Transparência } \\
\text { e prestação de } \\
\text { contas }\end{array}$ & $\begin{array}{l}\text { Identificar a existência e } \\
\text { quais ações, práticas ou } \\
\text { procedimentos para a realização } \\
\text { de metas; prestação de contas e } \\
\text { avaliação de resultados. }\end{array}$ & $\begin{array}{l}\text { OMT (2010); Duran (2013); Tomio } \\
\text { e Schmidt (2014) }\end{array}$ \\
\hline & $\begin{array}{l}\text { Compensações } \\
\text { obtidas }\end{array}$ & $\begin{array}{l}\text { Dependentes do desempenho } \\
\text { geral da governança. Deve- } \\
\text { se observar o retorno obtido } \\
\text { pela participação na rede e a } \\
\text { coerência desse benefício com } \\
\text { as necessidades da empresa e } \\
\text { da governança. }\end{array}$ & $\begin{array}{l}\text { D’Angella, De Carlo e Sainaghi } \\
\text { (2010) }\end{array}$ \\
\hline \multirow{2}{*}{\multicolumn{2}{|c|}{ 6) Padrão de Arranjo Institucional }} & $\begin{array}{l}\text { Identificar qual a formação de } \\
\text { arranjo institucional constituída } \\
\text { a partir da interação dos } \\
\text { atores locais: (1) normativo, (2) } \\
\text { empresarial, (3) empresa-líder e } \\
\text { (4) fragmentado. }\end{array}$ & $\begin{array}{l}\text { D’Angella, De Carlo e Sainaghi } \\
\text { (2010) }\end{array}$ \\
\hline & & Provan e Kenis (2008) & \\
\hline
\end{tabular}

Fonte: Elaborado pelo autor.

\section{PROCEDIMENTOS METODOLÓGICOS}

O presente estudo foi desenvolvido por meio das seguintes etapas: (a) seleção da unidade de análise, dos (b) atores inseridos no processo de governança, dos (c) sujeitos de pesquisa e das (d) possíveis fontes de coleta de dados.

Neste sentido, para alcançar o objetivo proposto, realizou-se um estudo de caso qualitativo e descritivo (Yin, 2005). Como fonte de informações foram coletados dados primários por meio de entrevistas semiestruturadas realizadas junto a três atores que atuaram como coordenadores do Fórum Regional de Turismo entre 2011 e 2018 (Quadro 2).

Justifica-se a escolha desses respondentes por esses terem sido responsáveis pela coordenação do Fórum Regional de Turismo, entre o período que compreende a sua institucionalização e o momento de realização da pesquisa.

Buscaram-se, por meio da interpretação das entrevistas semiestruturadas, em conjunto com os pressupostos teóricos apresentados, a análise profunda dos dados, a riqueza interpretativa, a contextualização do ambiente, os detalhes e as experiências, conforme propõem Sampieri, Collado e Lúcio (2006). 
Quadro 2: Identificação dos entrevistados

\begin{tabular}{|c|c|c|c|c|}
\hline & Data da entrevista & Duração & Formação do entrevistado & $\begin{array}{l}\text { Período de } \\
\text { atividade }\end{array}$ \\
\hline A & 3 de julho de 2018 & $39 \mathrm{~min}$ & $\begin{array}{c}\text { Bacharelado em Turismo / } \\
\text { Mestrado em Turismo Hotelaria } \\
\text { / } \\
\text { Doutoramento em } \\
\text { Administração } \\
\end{array}$ & $2011-2015$ \\
\hline B & 18 de junho de 2018 & $26 \mathrm{~min}$ & $\begin{array}{c}\text { Graduação em Turismo / } \\
\text { Mestrado em Engenharia } \\
\text { Florestal / } \\
\text { Doutorado em } \\
\text { Desenvolvimento Rural }\end{array}$ & $2015-2017$ \\
\hline C & 12 de julho de 2018 & $32 \mathrm{~min}$ & $\begin{array}{c}\text { Bacharelado em Turismo / } \\
\text { Mestrado e Doutorado em } \\
\text { Administração }\end{array}$ & 2017-atual \\
\hline
\end{tabular}

Fonte: Elaborado pelos autores.

Os entrevistados (Quadro 2) responderam a questionamentos relacionados aos mecanismos de governança do Fórum Regional de Turismo da Região Central, sendo que as perguntas norteadoras do processo de coleta de dados foram elaboradas tendo como base as dimensões e as variáveis propostas pelo modelo teórico sugerido por Xavier (2016), tal como fora sintetizado no Quadro 1.

A interpretação e a análise dos dados seguiram a metodologia de análise de conteúdo de Bardin (1977), por meio da qual se realizou a categorização do material coletado, estabelecendo-se, com base no modelo teórico proposto, informações que possibilitaram estabelecer o ajuste das categorias e as suas variáveis inicialmente previstos.

\section{RESULTADOS E DISCUSSÕES}

Os resultados do estudo encontram-se divididos em seis seções, conforme categorias propostas pelo modelo teórico apresentado por Xavier (2016). Sendo assim, a presente seção está organizada em: (1) contexto histórico e cultural; (2) formalização e estrutura, normas e regras; (3) interação entre os atores e uso dos recursos locais; (4) poder, confiança, conflito e interesses; (5) transparência e prestação de contas e (6) Padrão de Arranjo Institucional (6).

\section{Categoria 1: Contexto histórico e cultural}

De maneira inicial, identificou-se que o Fórum Regional de Turismo surgiu em decorrência de uma política pública de turismo no âmbito federal, oriunda do PRT. Essa determinava a constituição de Instâncias de Governança Regional e a respectiva inserção de municípios, agrupados em regiões, no Mapa do Turismo Brasileiro. Vale ressaltar que, de acordo com as diretrizes da versão 2018-2022 do PNT, apenas destinos regionalizados podem participar de editais de fomento e demais ações vinculadas ao Ministério do Turismo. 
De acordo com os relatos, observou-se que logo no começo foram realizadas oficinas de sensibilização e capacitação junto ao Fórum Regional de Turismo, visando atender às diretrizes estabelecidas pelo Ministério do Turismo e pelo PRT.

Notou-se, ainda, tal como fora relatado pelo entrevistado $A$, que o Fórum Regional de Turismo foi instituído, inicialmente, vinculado a um Curso de Gestão de Turismo de uma Instituição de Ensino Superior privada localizado no município de Santa Maria. As ações eram conduzidas pelos alunos do referido curso, os quais executavam as atividades propostas como bolsistas. O curso também era o responsável pela coordenação da Instância de Governança.

Em 2015, após a extinção do curso anteriormente citado, o Fórum Regional de Turismo teve sua coordenação transferida para o Curso de Gestão de Turismo da Universidade Federal de Santa Maria, ao qual está vinculado desde 2015 até os dias atuais, passando a ser coordenado pelos entrevistados B e C.

\section{CAtegoria 2: Funcionamento da Governança}

De acordo com a entrevistada A, no primeiro momento, os convites para participar do Fórum eram realizados para empreendedores turísticos locais, visando consolidar a Instância de Governança e fortalecer seu caráter Institucional. Com isso, esperava-se estimular a articulação dos municípios como um todo, e não individualmente, na busca pela criação coletiva de um Plano Regional de Turismo.

Posteriormente, conforme relatado pela entrevistada $B$, houve uma tentativa de formalização e criação de regimento interno. Para tal, solicitou-se um modelo junto à Secretária do Estado de Turismo, sendo informado, por este órgão, que não havia nenhum padrão a ser seguido, o que fez com essa iniciativa não tivesse continuidade pela falta de parâmetros e capacitação para elaboração do documento.

A necessidade pela formalização é indicada por Dredge (2006), Nordin e Svensson (2007), D'Angella e Haugland et al. (2011) como um dos elementos centrais para que a governança se desenvolva e, conforme aponta De Carlo e Sainaghi (2010), se consiga estimular a participação coletiva dos membros.

Naquele momento, o processo de tomada de decisões se baseava em deliberações coletivas, discutindo as pautas em grupo e por meio de votações, assim como o diálogo com a comunidade. Esse aspecto democrático relacionado à governança é salientado por Dredge (2006) como um dos pontos centrais para que se promovam o sentimento de bem-estar e a compreensão mútua, estimulando a cooperação.

Nos dias atuais, conforme relatado pelo entrevistado C (atual coordenador), - Fórum Regional de Turismo continua aberto a toda comunidade e não apenas a empresários ou instituições, esclarecendo-se, todavia, que apenas os gestores públicos têm direito a voto. Em relação às regras de conduta, nenhum entrevistado relatou problemas, salientando-se, contudo, o foco central do processo decisório nos representantes do Poder Público. 
O entrevistado C também destacou que pretende colocar em prática a elaboração de um estatuto e um regimento interno - procedimento recomendado por Haugland et al. (2011) como passo relevante para que se facilite a cooperação.

O entrevistado ainda relatou que, atualmente, o único mecanismo existente que formaliza a governança do Fórum é a sua legitimação oficial junto ao Ministério de Turismo, por meio da Secretaria Estadual de Turismo, o que o constitui como Instância de Governança Regional junto ao PRT. Ele ressaltou, ainda, a necessidade pela formalização por meio de um CNPJ.

\section{Categoria 3: Desenvolvimento da governança}

No que diz respeito ao desenvolvimento da governança, a entrevistada $A$ destacou o fato de as primeiras reuniões do Fórum e a sua respectiva gestão terem ocorrido em conjunto com o Fórum de Cultura, o que possibilitava que fossem discutidas pautas relativas à educação, à cultura e ao turismo conjuntamente. A mesma ressaltou que, além de facilitar a mobilização dos atores locais, tal iniciativa proporcionou o surgimento de projetos articulados.

No entanto, essa visão não foi corroborada pelo entrevistado $C$, atual coordenador, que aponta que as pautas levantadas nas reuniões conjuntas com a cultura, em diversas ocasiões, não convergem com as do Fórum de Turismo e com as diretrizes da Instância de Governança Regional. Para ele, isso dificulta o direcionamento de ações e desenvolvimento da estrutura cooperativa como um todo-além de dificultar o entendimento dos atores envolvidos acerca do papel exercido pela governança de cada setor.

Em relação à utilização dos atrativos turísticos locais, surgiu, em 2013, a Mostra Regional de Turismo, realizada anualmente em um Shopping Center localizado na cidade de Santa Maria (maior município da Região), por meio da qual são expostas a região turística e as suas potencialidades. Ressaltou-se, também, a viabilização da participação do Fórum Regional de Turismo no Festival de Turismo de Gramado (FESTURIS) - um dos mais relevantes eventos de turismo do Brasil -, fazendo dessa ação um relevante instrumento de promoção da região em questão.

Conforme apontado pelos entrevistados B e C, atenta-se, ainda, para a falta de diálogo com a comunidade como um problema a ser solucionado. Para eles, essa aproximação poderia resultar em ações pensadas de uma maneira global.

Tal visão tem sua relevância reforçada pelos estudos de Haugland et al. (2011), segundo os quais é necessário estimular a compreensão das interações existentes entre atores políticos, econômicos e sociais para que a governança alcance o êxito esperado.

Por fim, salienta-se que a governança não desenvolve parcerias e intercâmbios de experiências com outras Instâncias de Governança Regional, tal como fora relatado por todos os respondentes. Essa aproximação é ressaltada por Haugland et al. (2011) como relevante por propiciar a difusão, a troca e o conhecimento de práticas inovadoras e bem-sucedidas de cooperação. 


\section{Categoria 4: Coordenação da cooperação}

De acordo com as respostas dos entrevistados B e C, foram observadas dificuldades enfrentadas pela governança, tais como a falta de recursos financeiros e a carência por um coordenador e um grupo gestor que atuem exclusivamente na gestão do Fórum (atualmente a coordenação do Fórum fica a cargo de um professor universitário, que precisa conciliar as atividades profissionais e a gestão da Instância de Governança).

Essa carência é evidenciada nos estudos de Provan e Kenis (2008) e Wegner (2012), que veem na existência de um escritório central, que atue como uma entidade responsável pela coordenação e pela gestão das ações cotidianas relacionadas à governança, um facilitador para o funcionamento da mesma.

Outro argumento a ser considerado reside no fato que atualmente a coordenação do Fórum está vincula da a uma Instituição pública de Ensino Superior, o que gera entraves relacionados a obstáculos burocráticos e dificulta que os coordenadores da governança não consigam conciliar suas atividades profissionais com as do Fórum.

Outro ponto de destaque está no fato de os três entrevistados ressaltarem a importância de os municípios participarem do Fórum, pois todos consideram que esses destinos possuem os mesmos problemas ou vantagens similares. Para os entrevistados, a Instância de Governança deve ser vista pelos membros como um espaço de discussão de estratégias coletivas voltadas ao desenvolvimento turístico em nível regional. Todavia, todos salientaram a falta de envolvimento da comunidade e da Iniciativa Privada, sendo as decisões centradas no Poder Público.

Como principal fonte de conflito, os entrevistados relataram aspectos econômicos e a não convergência de interesses no que concerne à compreensão em relação aos objetivos do turismo em nível regional. Tal ponto é discutido nos estudos de Dredge (2006) e Pan (2010), que apontam para a necessidade de se compreender as relações e os interesses das partes envolvidas no processo cooperativo.

Já as divergências de interesses decorrem, especialmente, de um desconhecimento dos agentes locais sobre o real papel do Fórum Regional de Turismo, o que é reflexo das constantes trocas dos dirigentes municipais responsáveis pelo turismo e pela falta de capacitação dos mesmos.

Isso faz com que os membros estejam essencialmente preocupados com as demandas do município ao qual representam, não havendo uma confiança mútua entre os parceiros e um projeto coletivo voltado para o turismo, ponto apontado por Fernandes e Coriolano (2015) como essencial para o bom funcionamento da governança.

Os entrevistados não relataram ocorrências relacionadas a disputas de poder, especialmente pelo fato de o Fórum ser composto por dirigentes municipais, que geralmente estão envolvidos em suas demandas locais. Isso faz com que os gestores municipais não se interessem ativamente pela coordenação do Fórum, pois acabam vendo a Instância de Governança como uma obrigação extra. Compreender possíveis focos de disputa de poder é evidenciado por Beritelli, Bieger e Laesser (2007) como um 
elemento que gera um sentimento de confiança mútua entre os membros e favorece a interação e o foco em ações coletivas.

\section{Categoria 5: Resultados da GovernançA}

Em um primeiro momento, na gestão da entrevistada $B$, eram elaborados boletins bimestrais para relatar aos dirigentes municipais as ações que estavam sendo realizadas. Eles também eram informados sobre os avanços obtidos em relação às pautas discutidas em reuniões anteriores.

A mesma entrevistada ressaltou a dificuldade gerada pela não existência de um regimento interno, o que impossibilitava que houvesse cobrança pela participação efetiva dos membros e que discussões sobre possíveis contribuições financeiras fossem viabilizadas. A necessidade pela adoção de mecanismos de transparência e avaliação de resultados é apontada pela OMT (2010) e por Duran (2013) como centrais para que a cooperação se mantenha viva e para que a governança consiga desenvolver ações continuadas.

No mesmo sentido, o entrevistado $C$ relatou que a única cobrança feita está relacionada a editais para projetos que o Estado ou o Ministério do Turismo estabelecem; para os quais o não cumprimento pode vir a acarretar na exclusão do município da Instância de Governança Regional.

O entrevistado $C$ ainda esclarece que, diante do cenário destacado, as ações acabam sendo restritas àqueles que têm algum interesse específico ou dinheiro para financiar algumas atividades pontuais, o que torna a noção de individualidade muito presente, fazendo com que o olhar coletivo fique em segundo plano.

Sobre esse fato, D'Agnella, De Carlo e Sainaghi (2010) destacam a relevância da existência de mecanismos de prestação de contas, pois estes podem evidenciar aos membros o retorno obtido pela sua participação na governança e se os interesses individuais e coletivos estão sendo alcançados.

\section{PADRÃO DE ARRANJO INSTITUCIONAL}

De acordo com os elementos observados pelo estudo, pode-se classificar o Padrão de Arranjo Institucional do Fórum Regional de Turismo como uma configuração híbrida entre os modelos normativo e empresarial apresentados por D'Angella, De Carlo e Sainaghi (2010).

Com relação ao padrão normativo, nota-se a presença de autoridade pública, representada pela Secretaria de Turismo do Rio Grande do Sul, que, de forma exógena, seguindo as normativas do PRT e do Ministério do Turismo, determina as normas que regulam as estruturas e os mecanismos de funcionamento da Instância de Governança Regional. Salienta-se, todavia, que a adesão dos municípios no agrupamento regional é voluntária e não impositiva, além da possibilidade de as normas de governança poderem ser definidas e modificadas pelos próprios membros, por meio de um regimento interno elaborado endogenamente. Isso faz com que Fórum de Turismo também estabeleça interfaces com o padrão empresarial evidenciado por D'Angella, De Carlo e Sainaghi (2010). 
Sob outra ótica, tendo em vista os modelos básicos de governança apresentados por Provan e Kenis (2008), pode-se classificar a estrutura da rede de atores que compõem o Fórum Regional de Turismo como uma Governança Compartilhada, já que os municípios trabalham coletivamente dentro da Instância de Governança Regional, sem a existência de uma organização (um escritório) exclusiva que seja responsável pela gestão do Fórum.

\section{CONSIDERAÇÕES FINAIS}

Após a análise dos mecanismos de governança do Fórum Regional de Turismo - Região Central, considera-se que o mesmo ainda é incipiente e frágil, carecendo por avanços no que diz respeito à capacidade de gerar mobilização e envolvimento coletivo entre as partes envolvidas.

As fragilidades observadas podem ser elencadas da seguinte forma: (a) pouco entendimento dos atores envolvidos no processo sobre o papel e dos mecanismos de funcionamento da Instância de Governança Regional a qual pertencem; (b) baixa capacitação dos representantes municipais de turismo; (c) necessidade pela elaboração de um estatuto que estabeleça regras claras sobre o papel de cada um dos atores no processo de governança; (d) carência por uma interlocução direta do Poder Público com a iniciativa privada e a comunidade; (e) ausência de um plano regional de desenvolvimento turístico; e (f) ausência de fontes de recursos financeiros destinados à manutenção do Fórum.

Por meio da discussão realizada, considera-se que foram apresentadas fundamentações que favoreçam o entendimento e o aprofundamento acerca de um tema que carece de consolidação e uma melhor compreensão por parte de pesquisadores, profissionais e acadêmicos que buscam aplicar as diretrizes e desenvolver ações relacionadas ao PRT. Espera-se, igualmente, contribuir na condução de novos estudos que procurem abordar, compreender e analisar o relacionamento existente entre os atores locais, podendo o mesmo ser aplicado em outros contextos em que Instâncias de Governança Regional estejam presentes, sendo elas vinculadas ou não ao PRT.

Neste sentido, sugere-se que o estudo seja ampliado em pesquisas futuras, podendo ser investigadas as mesmas categorias aqui trabalhadas sob o ponto de vista dos demais integrantes da Instância de Governança Regional. Ou seja, da iniciativa privada e da comunidade envolvida direta e indiretamente com a atividade turística como um todo. Lembra-se que, no que diz respeito ao caso em questão, no atual momento a governança é composta somente por atores vinculados aos órgãos públicos de turismo dos municípios associados.

Nesse sentido, acredita-se que a presente pesquisa servirá para que atores ligados à atividade turística - sendo eles pertencentes à comunidade, ao setor público ou à iniciativa privada - passem a considerar a dinâmica de interconectividade que rege o setor, apontando para uma direção a partir da qual esses estabeleçam estruturas de governança eficazes nas regiões em que atuam, baseadas nos seus contextos históricos e suas realidades locais. 
No campo gerencial, salienta-se que a pesquisa irá auxiliar atores (públicos e/ ou privados) a se mobilizar para desenvolver redes de cooperação em regiões nas quais inexistam atividades colaborativas voltadas para o turismo, como também fornecer parâmetros para que agentes pertencentes a estruturas de governança consolidadas (ou não) possam repensar e avaliar suas práticas locais.

\section{REFERÊNCIAS}

Albers, S. (2005). The design of Alliance Governance Systems. Köln: KölnerWissenschaftsverlag.

Bardin, L. (1977). Análise de conteúdo. Lisboa: Edições 70.

Beaumont, N.; \& Dredge, D. (2010). Local tourism governance: a comparison of three network approaches. Journal of Sustainable Tourism, 18(1), 7-28.

Beritelli, P., Bieger, T., \& Laesser, C. (2007). Destination governance: using corporate theories as a foundation for effective destination management. Journal of Travel Research, 46, 96-107.

Boobbio, L. (2005). Governance multilivello e democrazia. Rivista delle Politiche Sociali, (2), 51-62.

Brunelli, M. Q., Macedo-Soares, T. D. L. V. A., \& Silva, R. F. (2012). Inovação e colaboração no turismo carioca: primeiras evidências empíricas. Revista Brasileira de Pesquisa em Turismo, 6(3), 340-356.

Cassiolato, J. E. \& Lastres, H. M. M. (2001). Aglomerações, cadeias e sistemas produtivos e de inovação. Brasília: IEL. Recuperado de http://www.ie.ufrj.br/gei/gil.

D'Angella, F., De Carlo, M., \& Sainaghi, R. (2010). Archetypes of destination governance: a comparison of international destinations. Tourism Review, 65(4), 61-73.

Dawkins, J. \& Colebatch, H. K. (2006). Governing through institutionalised networks: the governance of Sydney Harbour. Land Use Policy, 23, 333-343.

Dredge, D. (2006). Policy networks and the local organization of tourism. Tourism Management, 27(2), 269-280.

Duran, C. (2013). Governance for the tourism sector and its measuremente. UNWTO Statistics and TSA Issue Paper Series STSA/IP/2013/01. Recuperado de http://statistics.unwto.org/en/content/ papers.

Eagles, P. F. J. (2009). Governance of recreation and tourism partnerships in parks and protected áreas. Journal of Sustainable Tourism, 17, 231-248.

Fernandes, L. M. M. \& Coriolano, L. N. M. T. (2015). A governança na política nacional de regionalização do turismo: estudo dos grupos gestores dos destinos indutores do Ceará. Revista Turismo - Visão e Ação, 17(2), p.247-278.

Fischer, T. (1996). Gestão contemporânea, cidades estratégicas: aprendendo com fragmentos e reconfigurações do local. In T. Fischer. (org.). Gestão estratégica: cidades estratégicas e organizações local. Rio de Janeiro: FGV.

Haugland, S. A., Ness, H., Gronseth, B., \& Aarstad, J. (2011). Development of tourism destinations: na integrated multilevel perspective. Annals of Tourism Research, 38(1), 268-290. 
Ministério do Turismo. (2007). Programa de regionalização do turismo - roteiros do Brasil: Módulo Operacional 7 - Roteirização Turística. Brasília: Ministério do Turismo, Secretaria Nacional de Políticas de Turismo.

Ministério do Turismo. (2013). Plano Nacional de Turismo: 2013-2016. Brasília: Ministério do Turismo.

Ministério do Turismo. (2020). Mapa - Ministério do Turismo. Recuperado em 3 junho 2020, de http:// www.mapa.turismo.gov.br/mapa/init.html\#/home.

Nordin, S. \& Svensson, B. (2007). Innovative destination governance: the swedish ski resort Are. Entrepreneurship and Innovation, 8(1), 53-66.

Novelli, M, Schmitz, B, \& Spencer, T. (2006). Networks, clusters and innovation in tourism: A UK experience. Tourism Management, 27, 1141-1152.

Organização Mundial do Turismo. (2010). Proyecto gobernanza para el sector turismo: informe ejecutivo. Madrid: Estadísticas y Cuenta Satélite de Turismo.

Pan, J. (2012). Network governance and actor interaction in a coastal destination: a case study of Marstrand. Lund University: Campus Helsingborg.

Pforr, C. (2006). Tourism policy in the making: an australian network study. Annals of Tourism Research, 33(1), 87-108.

Provan, K. \& Kenis, P. (2008). Modes of network governance: structure, management and effectiveness. Journal of Public Administration Research and Theory, 18(2), 229-252.

Rodrigues, A. L. \& Malo, M. C. (2006). Estruturas de governança e empreendedorismo coletivo: o caso dos Doutores da Alegria. Revista de Administração Contemporânea, 10(3), 29-50.

Roth, A. L., Wegner, D., Antunes Jr., J.A.V., \& Padula, A. D. (2012). Diferenças e interrelações dos conceitos de governança e gestão de redes horizontais de empresas: contribuições para o campo de estudos. Revista de Administração, 47(1), 112-123.

Ruhanen, L., N. Scott, N., Ritchie, B., \& Tkaczynski, A. (2010). Governance: a review and synthesis of the literature. Tourism Review, 65(4), 4-16.

Sampieri, R. H., Collado, C. F., \& Lúcio, P. B. (2006). Metodologia de pesquisa. São Paulo: McGrall-hill Interamericana do Brasil Ltda.

Suzigan, W., Garcia, R., \& Furtado, J. (2007). Estruturas de governança em arranjos ou sistemas locais de produção. Gestão \& Produção, 14(2), 425-439.

Svensson, B., Nordin, S., \& Flagestad, A. (2005). A governance perspective on destination development: exploring partnerships, clusters and innovation systems. Tourism Review, 60(2), 32-37.

Theurl, T. From corporate to cooperative governance. (2005). In: T. Theurl. Economics of Interfirm Networks. Tubingen: Mohr Siebeck.

Timur, S. \& Getz, D. (2008). A network perspective on managing stakeholders for sustainable urban tourism. International Journal of Contemporary Hospitality Management, 20(4), 445-461.

Tomio, M. \& Schmidt, C. M. (2014). Governança e ações coletivas no turismo regional: a experiência dos empreendedores da região Oeste do Paraná. Revista Turismo - Visão e Ação, 16(3), p.710-739. 
Tur., Visão e Ação, v23, n1, p86-109, Jan./Abr. 2021 - Balneário Camboriú, Santa Catarina, Brasil

Villela, L. E. \& Pinto, M. C. S. (2009). Governança e gestão social em redes empresariais: análise de três arranjos produtivos locais (APLs) de confecções no estado do Rio de Janeiro. Revista de Administração Pública, 43(5), 1067-1089.

Xavier, T. R. (2016). Governança dos atores locais em um cluster turístico: a Associação de Produtores de Vinhos Finos do Vale dos Vinhedos (APROVALE) (Tese de Doutorado). Programa de PósGraduação em Administração, Universidade Federal de Santa Maria, RS, Brasil.

Zaccarelli, S., Telles, R., Siqueira, J., Boaventura, J., \& Donaire, D. (2008). Clusters e redes de negócios: uma nova visão para a gestão dos negócios. São Paulo: Atlas.

Wang, Y. \& Krakover, S. (2008). Destination marketing: competition, cooperation or competition?. International Journal of Contemporary Hospitality Management, 20(2), 126-141.

Wegner, D. (2012). Mecanismos de governança de redes horizontais de empresas: o caso das redes alemãs de grande porte. Revista Gestão Organizacional, 5(2), 214-228.

World Travel \& Tourism Council, WTTC. (2020). Economic Impact Reports 2020. Disponível em: <https:// wttc.org/Research/Economic-Impact>. Acesso em: 27 de maio 2020.

Yin, R. (2005). Estudo de caso: planejamento e métodos ( $3^{a}$ ed). Porto Alegre: Bookman.

Yüksel, F., Bramwell, B., \& Yüksel, A. (2005). Centralized and decentralized tourism governance in Turkey. Annals of Tourism Research, 32(4), 859-886.

\section{Contribuição de cada autor na construção do artigo}

Thiago Reis Xavier: Orientação do artigo, construção da metodologia de pesquisa, referencial bibliográfico, considerações finais e revisão do texto final.

Kézia Ávila Soares Totti: Bolsista de Iniciação Científica, elaboração do instrumento de coleta de dados, coleta de dados, análise de resultados e considerações finais.

Sandra Mari Flores Raddatz: Elaboração do instrumento de coleta de dados, coleta de dados, análise de resultados e considerações finais. 